\title{
Determinants of Job Satisfaction Among Agricultural Extension Workers in Southwest Ethiopia
}

\author{
Getahun Kassa \\ Department of Agricultural Economics, Mizan-Tepi Univeristy, Mizan-Teferi, Ethiopia \\ Email address \\ zgetah@gmail.com \\ To cite this article: \\ Getahun Kassa. Determinants of Job Satisfaction Among Agricultural Extension Workers in Southwest Ethiopia. American Journal of \\ Agriculture and Forestry. Vol. 4 , No. 5, 2016, pp. 112-117. doi: 10.11648/j.ajaf.20160405.11
}

Received: July 24, 2016; Accepted: August 1, 2016; Published: September 7, 2016

\begin{abstract}
This study assessed the level of job satisfaction and the factors associated with it among agricultural extension workers (DAs) in South West Ethiopia. Primary data were collected by using structured questionnaire from 170 DAs selected by using simple random sampling technique. DAs' job satisfaction was measured on an ordered 5-point Likert scale. Due to the categorical nature of the dependent variable, ordinal logit regression model was used to identify the factors affecting level of job satisfaction of DAs in the study area. The findings of the study revealed that the majority of DAs were dissatisfied with their job. The major causes for DAs' job dissatisfaction were work overload, extremely low payment, difficult \& disadvantaged work environment, poor social status, and poor interpersonal relationship with co-workers. However, a significant positive association was observed between job satisfaction and promotion policy. It is, therefore, important that the government should devise multiple package schemes to enhance the satisfaction level of DAs.
\end{abstract}

Keywords: Job Satisfaction, DAs, Ordinal Logit Regression, Agricultural Extension Service

\section{Introduction}

Agricultural development makes an important contribution to overall economic growth in many developing countries [1]. Agriculture employs $65 \%$ of Africa's labor force and accounts for $32 \%$ of the gross domestic product [2]. In Ethiopia, the contribution of agriculture is even far greater than other African nations. Agriculture contributes to $46 \%$ of GDP, $84 \%$ of export earnings, and it is a source of livelihood for the overwhelming majority $(80 \%)$ of the population [3]. However, agricultural productivity remains low relative to potential yields [4]. The ever-increasing decline in agricultural production has been primarily attributed to inappropriate and/or ineffective dissemination and use of technologies [5]. Thus, in order to achieve rapid agricultural growth with positive economy-wide linkages, it is necessary to engage middle farmers to adopt new technologies through agricultural extension service [6].

Agricultural extension service is the foundation for any meaningful development in agricultural sector [7]. Agricultural extension is basically aimed at providing farmers with essential knowledge and skills that would lead to increased production [8]. The effectiveness of agricultural extension work highly depends on extension professionals who are qualified, motivated, committed and responsive to the ever-changing social, economic and political environment [9]. Agricultural extension workers (DAs) can make extension services more effective by transferring up-to-date information to the farmers. Eventually, to achieve a sustained agricultural productivity growth, DAs' competence and their level of job satisfaction count most.

Job satisfaction is a general attitude towards an individual's current job and organization that encompasses the feelings, beliefs, and thoughts about that job [10]. Job satisfaction represents a combination of positive or negative feelings that workers have towards their work [11]. It is an extremely important area from an organizational perspective because of its correlation with other variables such as job motivation, organizational commitment, performance, turnover, and absenteeism that have a direct impact on an organization's effectiveness [12-13]. It also has major consequences for the wellbeing of the employee, coworkers, work groups, and managers [10]. However, the occurrence of these consequences will be probable if there is a lack of job satisfaction.

The job satisfaction of DAs in Ethiopia currently appears 
to be low. Many DAs seek alternative career opportunities due to low job satisfaction [4]. Most extension personnel are working under difficult and disadvantageous conditions characterized by lack of infrastructural facilities such as transportation problem, residence problem, remoteness, and health problems due to the absence of health services in rural area $[9,14]$. These and other problems have a triggering effect on their level of job dissatisfaction. In Southwest Ethiopia, in particular, despite the severity of the problem, no study has been conducted previously. This study, therefore, aimed at assessing the level of job satisfaction and the factors associated with it among DAs in Southwest Ethiopia. Studying job satisfaction is important because the effectiveness of agricultural extension service is predominantly determined by the relationship between extension workers and the job they do.

\section{Materials and Methods}

\subsection{Study Area}

The study was conducted in Bench Maji, Kaffa and Sheka zonal administrations of Southern Nations, Nationalities and People's Regional State (SNNPRS) in the south-west part of Ethiopia. In this region two main agroecological zones can be distinguished: the highland Dega zone (1800-2400masl) and the intermediate Weyna Dega zone (900-1800masl). A considerable amount of the region is still covered with natural vegetation; a tropical montane humid forests [15]. Agricultural practices are the sole livelihood sources for the majority of the inhabitants. Enset and maize are the major staple foods and mainly used for household subsistence. Coffee and honey are the major income sources.

\subsection{Data Collection}

Bench Maji, Kaffa and Sheka zonal administrations in Southwest Ethiopia were selected purposively based on agroecological similarity and similarity regarding agricultural extension service provision problems. A simple random sampling technique was employed to select a total of 170 respondents. Primary data were collected for the purpose of this study through structured questionnaire. Different parameters were used to collect information regarding the level and determinants of job satisfaction of the agricultural extension workers.

\subsection{Data Analysis}

To identify which job attributes contribute to job satisfaction, demographic factors [16] and other aspects of work that can be aligned to the theoretical background of the two-factor theory of Herzberg [17]were included. Except for demographic factors like age, sex, marital status, and work experience, other independent variables (work overload, payment, work environment, promotion policy, social status, participatory management and interpersonal relationship with co-workers \& supervisors) were measured using the five- point Likert-scale. Data were analyzed by using descriptive statistics tools (like mean, table and percentage), chi-square test, and econometric model using SPSS version 21 .

\subsection{Econometric Analysis}

Job satisfaction in this study was measured using a single-item measure. Respondents were asked to answer the question 'how satisfied are you with your overall job, considering all jobs facets?' on a five-point Likert scale'unsatisfied', 'somewhat satisfied', 'satisfied', 'highly' and' extremely satisfied'. However, because of few observations in the high satisfaction scale, the dependent variable was transformed into three values for job satisfaction: (1) dissatisfied, (2) neither dissatisfied, nor satisfied, (3) satisfied. Since the outcome variables for job satisfaction were ordered and categorical, the multinomial logit or probit models would fail to account for the ordinal nature of the dependent variables [18]. Thus, the most appropriate econometric estimation method to apply is ordinal logistic regression. The ordinal logit model has been used widely to analyze ranked responses [19]. The functional form of ordered logit model for job satisfaction is specified as follows $[18,22]$ :

$$
\mathrm{Y}^{*}=\sum_{k=1}^{k} \beta_{\mathrm{k}} x_{k i}+\varepsilon i .
$$

$\mathrm{Y}^{*}=$ is a continuous, unobserved and unmeasured latent variable whose values determine what the observed ordinal variable $\mathrm{Y}$ equals.

$\varepsilon=$ is a random disturbance term with zero mean and a standard normal or logistic distribution: $\varepsilon \sim \mathrm{N}(0,1)$.

The continuous latent variable $\mathrm{Y}^{*}$ has various threshold points. ( $\kappa$ is the Greek small letter Kappa.) Your value on the observed variable $\mathrm{Y}$ depends on whether or not you have crossed a particular threshold. Thus, when $\mathrm{M}=3$, what we do observed is;

$$
\left.\begin{array}{c}
\mathrm{Y}=1, \text { if } \mathrm{Y}^{*} \leq \mu_{1} \\
\mathrm{Y}=2 \text {, if } \mu_{1}<Y^{*} \leq \mu_{2} \\
\mathrm{Y}=3 \text {, if } \mu_{2}<Y^{*} \leq \mu_{3}
\end{array}\right\}
$$

Where: $\mathrm{Y}$, is observed in $\mathrm{j}$ number of ordered categories, $\mu \mathrm{s}$, are unknown threshold parameters separating the adjacent categories to be estimated with $\beta \mathrm{s}$.

The continuous latent variable $\mathrm{Y}^{*}$ can be rewritten as;

$$
\mathrm{Y}^{*}=\sum_{k=1}^{k} \beta_{\mathrm{k}} x_{k i}+\varepsilon=Z i+\varepsilon i
$$

The Ordered Logit Model estimates part of the above:

$$
\mathrm{Y}^{*}=\sum_{k=1}^{k} \beta_{\mathrm{k}} x_{k i}+\varepsilon=E(Y *)
$$

Note that, because of the random disturbance term, the unmeasured latent variable $\mathrm{Y}^{*}$ can be either higher or lower than Z. Note also that there is no intercept term. You then use the estimated M-1 cut off terms to estimate the probability that $\mathrm{Y}$ will take on a particular value. In this case since $\mathrm{M}=3$, the formulas are 


$$
\begin{gathered}
\mathrm{P}(\mathrm{Y}=1)=\frac{1}{1+\exp (Z i-k 1)} \\
\mathrm{P}(\mathrm{Y}=2)=\frac{1}{1+\exp (Z i-k 2)}-\frac{1}{1+\exp (Z i-k 1)} \\
\mathrm{P}(\mathrm{Y}=3)=1-\frac{1}{1+\exp (Z i-k 2)}
\end{gathered}
$$

The cumulative probabilities can also be computed using the form:

$$
\operatorname{Prob}(Y=j)=1-L\left(\mu_{j-1}-\sum_{k-1}^{k} \beta_{k} x_{k}\right)
$$

Where: $L($.$) represents cumulative logistic distribution.$

\section{Result and Discussion}

\subsection{Socioeconomic Characteristics of the Respondents}

Out of the total respondents, $15.3 \%$ of them were female and $84.7 \%$ of them were male. This shows more males are engaged in agricultural extension work in the study area as compared to females. Regarding marital status of the respondents, $68.2 \%$ of them were married and $31.8 \%$ of them were single. The mean age of the respondents was 29.69 years old. Out of the total respondents, $68.82 \%$ of the respondents lie in the age range of 20-30 years old, followed by $24.71 \%$ of respondents that lay in the age range of $31-40$ years old, and the remaining $6.47 \%$ of the respondents lie in the age range of above 40 years old.

Table 1. Demographic information of the respondents.

\begin{tabular}{lllll}
\hline Description & & Number & Percentage & Chi-square \\
\hline \multirow{2}{*}{ Sex } & Male & 144 & 84.7 & .141 \\
& Female & 26 & 15.3 & \\
MaritalStatus & Married & 116 & 68.2 & .521 \\
& Unmarried & 54 & 31.8 & \\
Agerange & $20-30$ & 117 & 68.82 & .286 \\
& $31-40$ & 42 & 24.71 & \\
\multirow{2}{*}{ Lengthofservice } & $41-50$ & 11 & 6.47 & \\
& $1-10$ & 146 & 85.89 & .765 \\
& $11-20$ & 20 & 11.76 & \\
\hline
\end{tabular}

Source: Own Survey

The mean years of work experience was 8.38 years. More than $85 \%$ of the respondents served as extension worker from 3-10 years, followed by $11.76 \%$ of the respondents whom served from 11-20 years, and the remaining $2.35 \%$ of the respondents served for more than 20 years as extension worker in the study area. Regarding educational attainment of the DAs, all of them were diploma holders graduated from different ATVET (agricultural technical vocational educational and training) colleges to facilitate the agricultural extension services in the country. Since all of the DAs are full-time government employees, they have no other alternative sources of income except their monthly earning as extension worker. However, it is important to note that personal factors have no significant effect on DAs' job satisfaction based on chi-square test (table 1).

\subsection{Level of Job Satisfaction}

To assess the job satisfaction level of the extension workers in the study area, 5 point Likert scale were used. Consequently, respondents were asked to rank their level of job satisfaction based on variables like work overload, income, work environment, social status, promotion policy, participatory management, and relationship with co-workers $\&$ supervisors. For each variable, 5 point Likert scale was constructed: $1=$ not at all satisfied, $2=$ not satisfied, $3=$ satisfied, $4=$ highly satisfied and $5=$ extremely satisfied. However, because of the limited observation in the highest category, the level of job satisfaction was transformed into three.

Table2. DAs level of job satisfaction.

\begin{tabular}{lll}
\hline Level of Job Satisfaction & Number & Percentage \\
\hline Unsatisfied & 71 & $41.8 \%$ \\
Neutral & 66 & $38.8 \%$ \\
Satisfied & 33 & $19.4 \%$ \\
\hline
\end{tabular}

Source: Own Survey

The table (table 2) showed that $41.8 \%$ of the DAs were not at all satisfied with their job, $38.8 \%$ of them were indifferent (neither satisfied nor dissatisfied), and the remaining 19.4\% of them were satisfied with their job. From the table (table 2) it can easily be understood that the overall level of job satisfaction of DAs' is in descending order from low to high. This finding is consistent with the finding in "Ref. [7]" who found below desirable level of work motivation of DAs.

\subsection{Factors Affecting Levels of Job Satisfaction}

With regard to identification of the determinants of job satisfaction, the ordered logit model was used. In this case, the model was employed to identify the probability that the respondent is unsatisfied, neutral, or satisfied with his/her job. This regression process is done with a maximum iteration of 100 and maximum step halving of 5. The removal probability in this case is taken as 0.1 ; the test for removal was "a Wald-test of removal" with the link function of "Logit".

Table 3. Model Fitting Information.

\begin{tabular}{lllll}
\hline Model & $\mathbf{- 2}$ Log Likelihood & Chi-Square & Df & Sig. \\
\hline Intercept Only & 255.194 & & & \\
Final & 168.350 & 86.845 & 13 & .000 \\
\hline
\end{tabular}

Looking at the model fit, a highly significant chi-square statistic $(p<.001)$ indicates that the model gives a significant improvement over the baseline intercept-only model. This basically tells us that the model gives better predictions than if we just guessed based on the marginal probabilities for the outcome categories [20].

Table 4. Goodness-of-Fit.

\begin{tabular}{llll}
\hline & Chi-Square & Df & Sig. \\
\hline Pearson & 129.028 & 127 & .433 \\
Deviance & 120.865 & 127 & .637 \\
\hline
\end{tabular}


The Pearson and Deviance goodness of fit statistics (table 4) test whether the observed data are inconsistent with the fitted model. If the significance values are large, the data and the model predictions are similar and that the model is a good model [20]. Therefore, the large values for significance (table 4) showed that the model fits the data well.

Table 5. Pseudo R-Square.

\begin{tabular}{ll}
\hline Cox and Snell & .400 \\
Nagelkerke & .456 \\
McFadden & .243 \\
\hline
\end{tabular}

The Nagelkerke $\mathrm{R}^{2}$ (table 5) indicates the model can account for $45.6 \%$ of the variance in job satisfaction.

Table 6. Test of Parallel Lines.

\begin{tabular}{lllll}
\hline Model & $\mathbf{- 2}$ Log Likelihood & Chi-Square & Df & Sig. \\
\hline Null Hypothesis & 168.350 & & & \\
General & 154.450 & 13.900 & 13 & .381 \\
\hline
\end{tabular}

In ordinal logistic regression models there is an important assumption which belongs to ordinal odds. According to this assumption parameters should not change for different categories [21]. If the assumption does not hold (if the chisquare value is significant), then you may want to consider another approach, such as the multinomial or generalized ordered logit models [22]. Since this chi-square value (table 6 ) is insignificant, the use of Plum is justified.

Table 7. Determinants of job satisfaction.

\begin{tabular}{llllll}
\hline Variables & Estimate & Std. Error & Wald & sign & Exp_B \\
\hline [Satisfaction=1] & -19.39 & 1.824 & 112.97 & .000 & .0000 \\
[Satisfaction=2] & -16.70 & 1.771 & 88.91 & .000 & .0000 \\
[work-overload=1.00] & -1.37 & .530 & 6.64 & .010 & .255 \\
[work-overload=2.00] & -.85 & .465 & 3.31 & .069 & .429 \\
[income=1.00] & -1.76 & 1.452 & 1.47 & .226 & .173 \\
[income=2.00] & -2.94 & 1.689 & 3.04 & .081 & .053 \\
[environment=1.00] & -14.32 & .403 & 1264.80 & .000 & .0000 \\
[environment=2.00] & -13.20 & .000 & & & .0000 \\
[social-status=1.00] & -1.86 & .983 & 3.56 & .059 & .156 \\
[social-status=2.00] & -1.53 & .951 & 2.57 & .109 & .218 \\
[advancement=1.00] & .812 & .459 & 3.13 & .077 & 2.252 \\
[management $=1.00]$ & .11 & .902 & .02 & .902 & 1.117 \\
[management $=2.00]$ & .40 & .875 & .21 & .645 & 1.497 \\
[relationship=1.00] & -2.41 & .940 & 6.58 & .010 & .090 \\
[relationship=2.00] & -.75 & .902 & .69 & .405 & .472 \\
\hline
\end{tabular}

Source: Own Computation

One of the independent variables that affected the job satisfaction of DAs is work overload. This variable is negatively and significantly associated with job satisfaction. Given all the other variables in the model held constant, in the first two analyses, Odds ratios less than one suggested that DAs are less likely to be satisfied with their present job in terms of work overload. This implies that DAs' engagement in non-extension activities can cause job dissatisfaction. In line with this finding, "Ref. [9]" revealed that DAs were challenged in performing their role effectively since they are work loaded in extension and non-extension activities. Another finding in "Ref. [23]" noted that high workload decreases agricultural extension workers' ability to make more accurate impact on their subjects and hence poor job performance in their agricultural extension work thereby leading to less satisfaction in their agricultural extension work.

In terms of income, the regression result revealed that this variable is negatively and significantly associated with job satisfaction. Given all the other variables in the model held constant, in the second analysis, an odd ratio less than one suggested that DAs are less likely to be satisfied with their present job. This implies that DAs' inability to lead a decent life with their salary can decrease the probability of their being satisfied with their job. However, there is no difference in the likelihood of being at satisfaction category 1 , because this category is not statistically significant. In line with this finding, "Ref. [24]" revealed that there was a significant negative relationship between monthly salary and job satisfaction. Another finding in "Ref. [9]" revealed that DAs are dissatisfied with their monthly paid salary and allowance obtained. In "Ref. [14]" and "Ref. [7]" it is noted that the work motivation and performance of DAs is hindered by an extremely low salary and lack of incentives.

Regarding the conduciveness of work environment, all have negative coefficients in the model. These characteristics are associated with an extension worker being in lower job satisfaction categories rather than in higher category. Given all the other variables in the model held constant, in the first two analyses, this variable is negatively and significantly associated with job satisfaction with odds zero, suggesting that there is zero probability of being in the higher level of job satisfaction category in terms of work environment. This implies that working in a difficult and disadvantaged physical environment negatively affects job satisfaction. In line with this finding, "Ref. [14]" found that DAs performance is hindered by their work condition. In their finding, the researchers noted that DAs are found working under areas characterized by lack of infrastructural facilities such as transportation problem, residence problem, remoteness, and as well many of them work in areas characterized by lack of mobility freedom. Another finding in "Ref. [7]" revealed that work location negatively and significantly influenced work motivation of DAs.

In terms of social status, a significant negative association with job satisfaction was observed. All categories of this variable have negative coefficients in the model corresponding odds that are significantly less than 1 . Given all the other variables in the model held constant, smaller odds ratio in all analysis suggested that these characteristics are associated with being in lower level of satisfaction categories rather than in higher category. This implies that a considerable decline in respect in the society (low stature) for agricultural professionals causing job dissatisfaction and forcing professionals to look for other career opportunity. In line with this finding, "Ref. [25]" noted that the involvement of extension workers in non-extension activities led to the undermining of their credibility and reputation whereby many people tended to view them as government prolocutors rather than facilitators of agricultural development endeavors. 
The presence of fair promotion policy (advancement) in the organization has positively and significantly associated with the level of job satisfaction. Given all variables in the model held constant, odd ratio with value more than one in the first analysis suggesting that DAs are more likely to be in the highest level of job satisfaction category. This implies that a better and fairer promotion policy can be a driving force for positive job satisfaction. However, there is no difference in the likelihood of being at or above satisfaction category 2, because these categories are not statistically significant. In line with this finding, "Ref. [23]" revealed that staff promotion has a significant and positive influence on agricultural extension workers job satisfaction. In the finding, it was noted that regular promotion of agricultural extension workers implies increased motivation to carry out the appropriate tasks more accurately, which is as a driving force to improving performance in their agricultural extension work thereby deriving higher satisfaction in the job [23]. Another finding "Ref. [7]" also revealed that policy environment of Extension organization has a positive and significant impact on work motivation of DAs, which positively impact on their job satisfaction.

The presence of good relationship with co-workers in the organization has negatively associated with the level of job satisfaction. It was the relationship between DAs and their superiors, subordinates, colleagues and others which included quality of social life at work. All categories of this variable have negative coefficients in the model with corresponding odds that are less than 1 . Given all variables in the model held constant, in the first analysis, odds ratio with value less than one suggesting that DAs are more likely to be in the lowest level of job satisfaction in terms of interpersonal relationship. This implies that unhealthy and strained relationship between co-workers can be the cause of job dissatisfaction. However, there is no difference in the likelihood of being at or above satisfaction category 2, because these categories are not statistically significant.

\section{Conclusion and Recommendation}

There search result revealed that the majority of agricultural extension workers were not satisfied with their job. Though DAs are the key agents of change to bring an improvement in the living standards of millions of farmers, their level of job satisfaction was affected by factors like extra work burden, extremely low salary, unfavorable work environment, poor social status, and poor interpersonal relationships with co-workers and supervisors. Their negative feelings about their job have been undoubtedly denting the effectiveness of extension service in the area. Therefore, the government and other stakeholders should emphasize on the causes of DAs job dissatisfaction and should strive to improve those problems by devising different package schemes like delegating specific responsibilities, devising different incentive packages, creating favorable physical environment, and improving interpersonal relationship with co-workers and supervisors.

\section{References}

[1] Bage L, (2006). Seeds of hope: Agriculture and Economic Development. Available on the internet at www. unep. org.

[2] NEPAD Planning and Coordinating Agency (NPCA), (2013). Review of Agricultural Technical Vocational Education and Training (ATVET) in Africa-Best Practices from Benin, Ethiopia, Namibia and Sierra Leone.

[3] Kassahun B, (2012). The Political Economy of Agricultural Extension in Ethiopia: Economic Growth and Political Control. Working Paper, 042. Available on www. Futureagricultures. org.

[4] International Food Policy Research Institute (IFPRI), (2009). Review and Recommendations for Strengthening the Agricultural Extension System in Ethiopia.

[5] International Livestock Research Institute (ILRI), (2008). Concepts and practices in agricultural extension in developing countries: A source book.

[6] Mellor J. W, and Dorosh P, (2010). Agriculture and the Economic Transformation of Ethiopia. Development Strategy and Governance Division, International Food Policy Research Institute-Ethiopia Strategy Support Program 2, Ethiopia. Working Paper No. ESSP2010.

[7] Dessalegn G, (2014). Analyzing Determinants of Development Agents' Motivation in Agricultural Extension Services Provision: A Case from South West Shoa Zone, Oromia Regional State, Ethiopia: An Ordered logit Regression Model approach. International Journal of Agricultural Extension and Rural Development Vol. 1(3), pp.026-030, September, 2014.

[8] Tsion T, Ranjan SK, and Teklu T, (2010). Effectiveness of training offered by Ethiopian Institute of Agricultural Research to farmers: The case of Holetta, Melkassa and Debre Zeit Agricultural Research Centres, Ethiopia. Afri. J. Agri. Res. 5(7): 500-513.

[9] Gebrehiwot W, Kinfe A, Deribe K, (2012). Challenges of Development Agents (DAs) Performance in Technology dissemination: A Case from Southern, Nation, Nationalities and Peoples Regional State (SNNPRS), Ethiopia. Scholarly J. Agric. Sci. 2(9): 208-216.

[10] Bitsch V, and Hogberg M, (2004). Employee Retention: Components of Job Satisfaction of Green Industry Employees. Selected Paper prepared for presentation at the American Agricultural Economics Association Annual Meeting, Denver, Colorado, August 1-4, 2004.

[11] Aziri B, (2011). Job Satisfaction: A Literature Review. Management Research and Practice Vol.3 Issue 4 (2011) PP: 77-86.

[12] Peerbhai R, (no date). Job Satisfaction at it SMES in Durban.

[13] Seid M, Muluken T, and Mulugeta T, (2013). Assessment of Job Satisfaction among Pharmacy Professionals in South-West Ethiopia. IJPSR, 2013; Vol. 4(6): 2351-2358. 
[14] Asayehegn K, Weldegebrial G, and Kaske D, (2012). Effectiveness of development agents' performances in agricultural technology dissemination: The case of Southern Nations Nationalities and Peoples Regional State (SNNPRS), Ethiopia. Journal of Agricultural Extension and Rural Development Vol.4 (17), pp. 446-455, 21 September, 2012. Available online at http://academicjournals.org/JAERD.

[15] Beijnen J, Mostertman I, Renkema G, Vliet J, (2004). Baseline description of project area. Summary of appraisal data at Kebele and Got level. Wageningen University, The Netherlands.

[16] Reudavey, Peter G, Ling,Chia C, and Dickie L, (2003). 'Influenceon Aviation Employees' Performance in South East Asia: A Multivariate Analysis of Job Satisfaction Variables", Working Paper Series, School of Management, Curt in University of Technology, Australia.

[17] Herzberg F, Mausner B, \& Snyderman B. B, (1959). The motivation to work. New York: John Wiley \& Sons.

[18] Green W. H, (2000). Econometric analysis. Prentice-Hall Inc: $4^{\text {th }}$ ed.: New Jersey. 679-850.

[19] Greene W, and Hensher D, (2009). Ordered Choices and Heterogeneity in Attribute Processing. J. Transp. Econ. Pol., 44(3): 331-364.
[20] Elamir E, and Sadeq H, (2010). Ordinal Regression to Analyze Employees' Attitudes towards the Application of Total Quality Management. Journal of Applied Quantitative Methods, Vol 5, No 4.

[21] Ari E, and Yildiz Z, (2014). Parallel Lines Assumption in Ordinal Logistic Regression and Analysis Approaches. International Interdisciplinary Journal of Scientific Research, Vol. 1 No. 3 December, 2014.

[22] Williams R, (2010). Ordered Logit Models. Overview. University of Notre Dame, http://www3.nd.edu/ rwilliam/

[23] Okwoche V, Eziehe J. C, and Agabi V, (2015). Determinants of Job Satisfaction among Extension Agents in Benue State Agricultural and Rural Development Authority (Bnarda), Benue State, Nigeria. European Journal of Physical and Agricultural Sciences, Vol. 3 No. 2, 2015.

[24] Ali A, Fereshteh F, and Zahra K, (2008). Personal Characteristics Affecting Agricultural Extension Workers' Job Satisfaction Level. Journal of Social Sciences 4 (4): 246-250, 2008.

[25] Belay Kassa, (2002). "Constraints to Agricultural Extension Work in Ethiopia: An Insider's View". South African Journal of Agricultural Extension (31): 63-79. 